\title{
Effects of the production season and the size of onion bulbs (Allium cepa L.) on their storage life at room temperature and humidity in Burkina Faso.
}

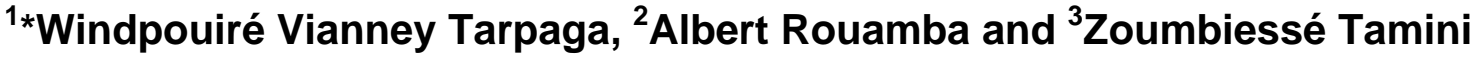 \\ ${ }^{1}$ Horticultural engineer at the Institute for Environment and Agricultural Research (INERA) / \\ Burkina Faso Tél : (00226)70708061 \\ Email : tarwendp@yahoo.fr \\ ${ }^{2}$ Vegetables Breeder at the Institute for Environment and Agricultural Research (INERA) / \\ Burkina Faso \\ ${ }^{3}$ Department of Plants biology and physiology, University of Ouagadougou (U.O) / Burkina \\ Faso
}

\begin{abstract}
The lack of cool storage rooms causes enormous losses of bulbs for a great number of onion growers. An assessment is done to determine the effects of growing season and the size of onion bulbs on their storage life. The trial was carried out in Ouahigouya in Northern Burkina Faso, in the Sudano-Sahelian climatic zone. Onion bulbs were grown in two different seasons and sorted into classes according to the one bulb weight. According to the growing season of bulbs, the late season is better than the normal season. Over 150 days of storage, the percentages of weight losses were $49.3 \pm 3 \%$ for the bulbs from late season and $57.7 \pm 1.8 \%$ for those from normal season. According to the size of bulb, the large bulbs have recorded more weight losses (85.6 \pm $1.3 \%)$ than medium bulbs $(77.9 \pm 0.5 \%)$ or small bulbs $(79.0 \pm 2.9 \%)$, over a time of 240 days of storage. These results are useful for the storage of onion bulbs at room temperatures. They will help producers to optimize the losses of bulbs and to make more profit by keeping their harvest until to carry best market prices.
\end{abstract}

Keywords: Onion, Conservation, Bulbs loss, Season, Allium cepa L.

\section{INTRODUCTION}

Onion bulb conservation is an alternative method to extend the period of availability of bulbs on the local markets. It can also help maintain onion prices at levels that can be profitable to the growers. However, like most fresh vegetables, long term conservation often requires cold storage or for lack of this, well ventilated rooms. The construction and the maintenance of such storage facilities requires large investments. Stores using fans also require electricity to function, an input that is very expensive that cannot be afforded by the small producers in West Africa. Most farmers in this region have no modern storage facilities. They rely on simple naturally ventilated barns such as the one used in our study.

A lot of work has been conducted to understand the causes of conservation losses of onion bulbs in storage, especially at room temperature and humidity. In the U.K, Stow and Ward (1978) reported that the major causes of bulb deterioration during conservation are in order of importance, rotting, dehydration and sprouting. High temperatures, 30- $35^{\circ} \mathrm{C}$ encouraged bulb rot caused by Aspergillus niger while low temperatures favored bulb rot caused by Botrytis alli (Tucker et al., 1977; Stow and Ward, 1978). Ward (1976) reported that respiration was responsible for less than $20 \%$ of physiological weight loss in the U.K.

The ability to store for long duration is also a varietal characteristic of onions (Brewster, 1994). Foskett and Peterson (1950) found a strong positive correlation between the content of dry matter and resistance of bulbs to sprouting in a range of U.S onion cultivars.

Several authors reported that cultural practices have an effect on the losses of onion bulbs in storage. Tucker and Drew (1982) have shown that in the U.K. sprouting is earlier in bulbs harvested late and that the rate of bulb rot in conservation increases with the lateness of harvesting. Wall and Corgan (1994) in New Mexico, USA also found that when the harvesting of bulbs is delayed till after the fall or 'tops down' of $80 \%$ of the leaves, there was an increase in the rate of storage rot. Fertilization with $\mathrm{CaCl}_{2}$ has been shown to improve the firmness of the scales in 
Georgia, USA (Coolong and Randle, 2008). Regarding the influence of bulb size, it has long been known to seed producers that small or medium sized bulbs last better in storage than larger bulbs (Ward, 1979; Peters, 1990). The main objective of this study is to identify the best season to produce onions bulbs for storage in soudano-sahelian climatic conditions. It also aimed to determine the optimal size of bulbs according to their production season, for room temperature storage.

\section{MATERIALS AND METHODS}

Materials: The experiment was conducted with seed and bulbs of 'cv. Violet de Galmi', a short day onion variety, using a line produced by the Environment and Agricultural Research Institute (INERA) of Burkina Faso (BF) and named $12 \mathrm{BF}$.

The trials were conducted at Ouahigouya, in northern $\mathrm{BF}$, in a Soudano-sahelian climate. The coordinates of the experimental site are $13^{\circ} 33^{\prime} \mathrm{N}$ and $2^{\circ} 26^{\prime} \mathrm{W}$ with an average altitude of $332 \mathrm{~m}$. The soil is characterized by a pH of 5.7 and silty clay texture.

The store was built on $12 \mathrm{~m}^{2}$ with sun dried brick, covered with asbestos sheets. These sheets were insulated underneath by a grass thatch to reduce the warming up caused by the sun. The store was well ventilated by doors which were closed only at night and three windows which measured $0.6 \mathrm{~m}^{2}$ each. These windows had screen and were never closed. The bulbs were spread on wooden racks, measuring $1.20 \mathrm{~m}$ long $\times 0.90 \mathrm{~m}$ wide and with a depth of 0.10 $\mathrm{m}$. The racks were lined with a wire net large enough to allow a good circulation of air between the bulbs. The weighing of bulbs were done with a dial scale dynamometer. The variations of temperature in the store and the relative humidity of air were recorded during the trials using an electronic hygrothermometer, model Testo $177 \mathrm{H}_{1}$.

\section{METHODS}

Production of mother bulbs: Two tests were done for this study, the first one in 2007 and the second one in 2008. Three growing seasons called normal, late and early have been defined. The normal season goes from mid October to mid December. The early season was defined as any transplanting done before mid October, and the late season, as any transplanting done after mid December. The bulbs were grown into the early and late seasons in 2007 and into the normal and late seasons in 2008. Tillage was done using oxen drawn plough, then the soil was leveled and the plot delimited. Fertilizer N.P.K (14-2314) at the rate of $90 \mathrm{~g} / \mathrm{m}^{2}$ and organic matter at the rate of $5 \mathrm{~kg} / \mathrm{m}^{2}$ were incorporated in the soil. One month after transplanting, nitrogen in urea form was applied by fertigation at the rate of $500 \mathrm{~g}$ per week for a total quantity of $2 \mathrm{~kg}$. The transplanting was done in three double rows per plot, with a spacing of $0.30 \mathrm{~m}$ between double rows and $0.12 \mathrm{~m}$ between plants in the same row and $0.20 \mathrm{~m}$ between plants of twin rows. The plant density was 50 plants $/ \mathrm{m}^{2}$. The plants are obtained from a nursery sown for that purpose in the experimental site. The irrigation was done according to the season and the phenological stage of plants, by a drip system. Irrigation was stopped when $50 \%$ of the plants have their leaves fallen over. Harvesting was done only on plants that have not shown any floral stalks, had their neck closed and their top well fallen over. Further details of specific crop management methods for each production season are recorded in table 1.

Table 1. Characteristics of growing seasons of bulbs

\begin{tabular}{|c|c|c|c|c|}
\hline \multirow[b]{2}{*}{ Parameters } & \multicolumn{2}{|c|}{ Year 2007} & \multicolumn{2}{|c|}{ Year 2008} \\
\hline & $\begin{array}{l}\text { Early } \\
\text { Season }\end{array}$ & Late Season & $\begin{array}{l}\text { Normal } \\
\text { Season }\end{array}$ & Late Season \\
\hline Sowing date & $17 / 08 / 06$ & $03 / 12 / 06$ & 07/10/07 & $04 / 12 / 07$ \\
\hline Transplanting date & 04/10/06 & $27 / 01 / 07$ & $14 / 11 / 07$ & $22 / 01 / 08$ \\
\hline Lifting Date & $07 / 02 / 07$ & $02 / 05 / 07$ & 07/03/08 & $28 / 05 / 08$ \\
\hline Storage date & $25 / 02 / 07$ & $11 / 05 / 07$ & $15 / 03 / 08$ & 13/06/08 \\
\hline Storage duration (days) & 159 & 84 & 240 & 150 \\
\hline $\begin{array}{l}\text { Daily doses of irrigation }(\mathrm{mm}) \\
\text { - From transplanting to } 60^{\text {th }} \text { day of age } \\
\text { - From } 60^{\text {th }} \text { day to when } 50 \% \text { of plants had collapse } \\
\text { foliage }\end{array}$ & $\begin{array}{l}4 \\
6\end{array}$ & $\begin{array}{l}6 \\
8\end{array}$ & $\begin{array}{l}4 \\
8\end{array}$ & $\begin{array}{l}6 \\
8\end{array}$ \\
\hline
\end{tabular}

Source: data collected from the trial

Storage of bulbs: The harvested bulbs were kept in the shade for 9 to 18 days for a complete dehydration of the leaves. Damaged and rotten bulbs as well as bulbs with non closed neck were discarded. Two 
storage trials were conducted respectively in 2007 and 2008. For each trial, bulbs from two growing seasons of the same year were evaluated.

For the trial in 2007 , healthy bulbs were divided into three batches near-identical by the weight and by the number of bulb (table 2a).
In 2008, the bulbs harvested in normal season were sorted according to their sizes into three classes that contained respectively big, medium and small bulbs. For the bulbs produced in late season, two classes consist of small and very small bulbs were built up. The range of weight of one bulb was determined by weighing 40 bulbs in each class. The bulbs of each class have been divided in three replicates (table $2 b$ ).

Table 2a. Characteristics of stored bulbs by growing season in 2007

\begin{tabular}{|l|c|c|}
\hline Parameters & Early Season & Late Season \\
\hline Range of average weight of one bulb by batch (g) & $107.5-117.94$ & $61.84-67.33$ \\
\hline Weight of bulbs by batch (kg) & $4.47 \pm 0.15$ & $4.80 \pm 0.20$ \\
\hline Average number of bulbs by batch & $39.67 \pm 0.58$ & $75.67 \pm 0.58$ \\
\hline Total number of bulbs stored & 119 & 227 \\
\hline Total weight of bulbs stored (kg) & 13.40 & 14.45 \\
\hline
\end{tabular}

Source: data collected from the trial

Table 2b. Characteristics of stored bulbs by growing season in 2008

\begin{tabular}{|l|c|c|c|c|c|}
\hline \multirow{2}{*}{ Parameters } & \multicolumn{3}{c|}{ Normal Season } & \multicolumn{2}{c|}{ Late Season } \\
\cline { 2 - 6 } & Large & Medium & Small & Small & $30-50$ \\
\hline $\begin{array}{l}\text { Weight ranges of the various } \\
\text { bulb size classes (g) }\end{array}$ & $300-200$ & $200-150$ & $150-50$ & $150-50$ & $3.58 \pm 0.08$ \\
\hline Weight of bulbs by batch (kg) & $9.63 \pm 0.29$ & $11.68 \pm 0.20$ & $6.37 \pm 0.15$ & $4.67 \pm 0.08$ & $80.00 \pm 0.00$ \\
\hline $\begin{array}{l}\text { Average number of bulbs by } \\
\text { batch }\end{array}$ & $35.00 \pm 0.00$ & $65.00 \pm 0.00$ & $62.33 \pm 0.58$ & $60.00 \pm 0.00$ \\
\hline Total number of bulbs stored & 105 & 195 & 187 & 180 & 240 \\
\hline $\begin{array}{l}\text { Total weight of bulbs stored } \\
(\mathrm{kg})\end{array}$ & 28.90 & 35.05 & 19.10 & 14 & 10.75 \\
\hline
\end{tabular}

Source: data collected from the trial

The bulbs for each replicate in both 2007 and 2008 were arranged on the racks and placed in the storage barn. Observations were made at intervals of 15 days. Rotten, dried and sprouting bulbs were counted and removed. Then, the weights of the remaining healthy bulbs were measured. The difference between two consecutive measurements gave the weight lost in storage (Tucker et al., 1977; Ramin, 1999). This weight lost was then transformed into percentage. Ten-day period averages of temperature and humidity were calculated from data recorded per hour. The graphs of these two parameters for trials in both 2007 and 2008 were showed in fig. 1a and $1 \mathrm{~b}$.

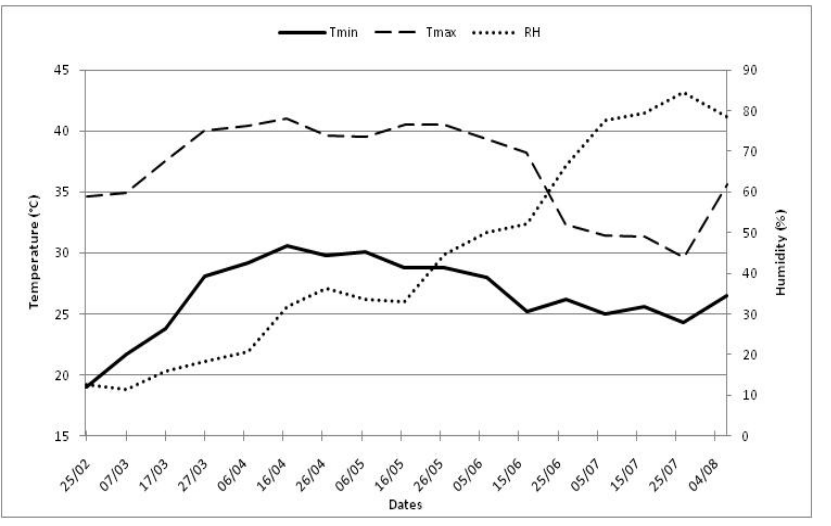

Fig 1a. Evolution by 10 day period of temperature and humidity in the store during storage in 2007

Tmin $=$ minimum average of temperature Tmax = maximum average of temperature $\mathrm{RH}=$ average of air relative humidity 
Data collection and statistical process: The bulbs were not put in storage at the same date because their growing season was different in the two trials. So, before the assessment of the effect of growing seasons on the weight losses, an adjustment was necessary. The dates of storing of bulbs from the late seasons were considered as origin to calculate the cumulated percentage of losses. The comparison of total losses, according to the season of bulbs production were done at 84 days of storage in 2007. The same type of comparison were done for trial in 2008, at 84 and 150 days of storage. According to the bulb size, comparisons were done at 75, 90 and 240 days of storage, for the bulbs from normal season. For the bulbs produced in late season, comparison were done at 135 and 150 days of storage. Mean comparison tests were done using Bonferonni multiple - comparison tests procedure by the statistical program STATA 10.0.

\section{RESULTS}

Effect of growing seasons of bulbs: During the storage of bulbs in 2007, there has been an uneven development of the rate of weight losses of the two seasons (fig 2). It was noted however that for early bulbs, losses increased steadily and reached a maximum after three months. That was followed by a sudden decline. The two week average of weight losses computed during the duration of the trial was $3.01 \pm 2.33 \%$ for the bulbs produced in early season and $4.29 \pm 3.78 \%$ for the bulbs from late season. The difference between these values was not significant $(P=0.19)$.

The comparison of percentages of total losses at 84 days of storage showed no significant difference $(P=$ 0.29 ) between the bulbs produced in early season and those from the late season. The losses were calculated from the date of storage of the bulbs produced in late season (table 3).

Table 3. Effect of growing season on the percentage of weight losses of bulbs during the storage in both 2007 and 2008

\begin{tabular}{|c|c|c|c|}
\hline \multirow{2}{*}{ Years } & Storage duration (days) & Growing season of bulbs & $\begin{array}{c}\text { Weight losses of bulbs } \\
\text { (\%) }\end{array}$ \\
\hline \multirow{2}{*}{2007} & \multirow{2}{*}{84} & Early & $24.4^{\mathrm{a}} \pm 3.5$ \\
\cline { 2 - 4 } & \multirow{2}{*}{2008} & Late & $30.0^{\mathrm{a}} \pm 7.2$ \\
\cline { 2 - 4 } & \multirow{2}{*}{84} & Normal & $35.2^{\mathrm{a}} \pm 3.9$ \\
\cline { 2 - 4 } & \multirow{2}{*}{150} & Late & $36.8^{\mathrm{a}} \pm 2.7$ \\
\cline { 2 - 4 } & & Normal & $57.7^{\mathrm{a}} \pm 1.8$ \\
\cline { 2 - 4 } & & Late & $49.3^{\mathrm{b}} \pm 3.0$ \\
\hline
\end{tabular}

In the same year and for the same storage duration, averages of treatments affected by the same letter do not differ significantly at $5 \%$ level in Bonferroni multiple-comparison

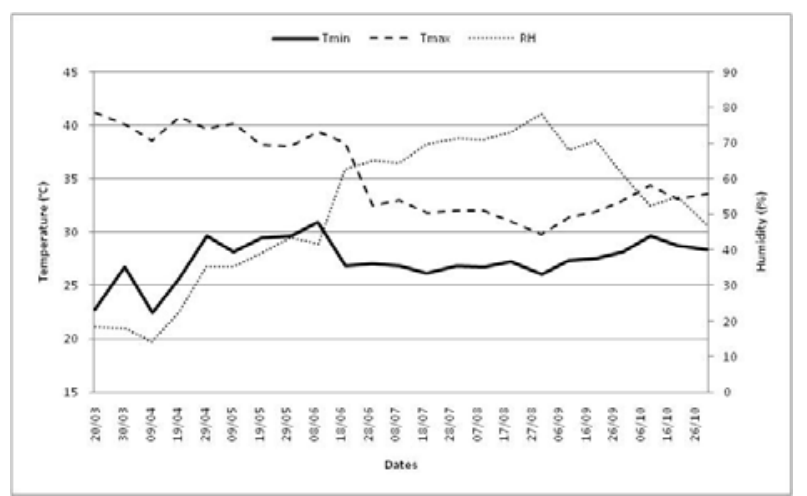

Fig 1 b. Evolution by 10 day period of temperature and humidity in the store during storage in 2008.

Tmin = minimum average of temperature Tmax = maximum average of temperature $\mathrm{RH}=$ average of air relative humidity
During the storage of bulb in 2008, the evolution of weight losses showed two phases more or less pronounced according to the production season of bulbs (fig 3 ). There was a significant increase in the rate of losses of bulbs, after 42 days of storage for the late season and after 44 days for the bulbs from normal season. This phase was followed by a gradual decline of rates of losses irrespective of the season of bulb production. The amplitude of variations was more important for the normal season than that of the late season. A significant difference $(P=0.03)$ was observed between the two weeks average rate of weight losses of bulbs from the normal season $(9.1 \pm 5.4 \%)$ and that of bulbs from the late season $(5.9 \pm 2.8 \%)$. Comparison of the total percentage of losses has shown no significant difference over a time of 84 days between bulbs of the two seasons. However, over a time of 150 days a significant difference $(P=0.01)$ appeared between the treatments (table 3 ). Furthermore, at 150 days of 
storage, it has been recorded $57.7 \pm 1.8 \%$ for the bulbs from normal. After the same time of storage, $49.3 \pm 3.0 \%$ of losses were recorded for bulbs produced in late season (Table 3 ).

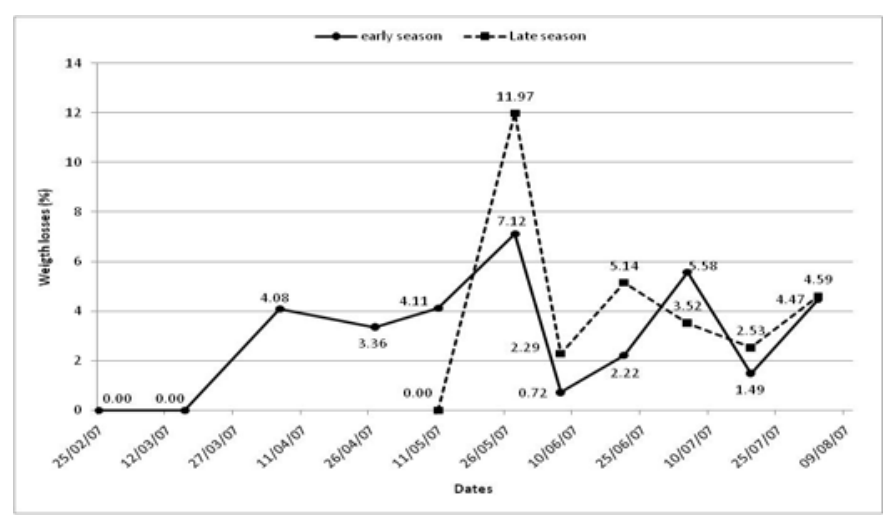

Fig 2: Evolution of the rates of weight loss of bulbs from early and late season over the time of storage in 2007
Effect of bulbs size: The tests have shown a significant difference $(P=0.03)$ between the weight losses of large bulbs $(54.2 \pm 5.9 \%)$ and medium bulbs $(41.8 \pm 3.6 \%)$ at 75 days of storage. The recorded percentage of losses for small bulbs was $50.0 \pm 1.4 \%$ (table 4). A high significant difference was found between the classes of large and medium bulbs at 90 days $(P=0.007)$ and 240 days $(P=$ 0.004 ) of storage (table 4). Over the time of 240 days of storage, the losses were higher for large bulbs $(85.6 \pm 1.3 \%)$ than for medium bulbs $(77.9 \pm 0.5 \%)$ or small bulbs $(79.0 \pm 2.9 \%)$. For the bulbs produced in late season, there was a significant difference $(P=$ 0.04 ) in weight losses at 135 days of storage. The small bulbs recorded a cumulative rate of weight losses of $51.1 \pm 1.8 \%$ after this time of storage. But over a time of 150 days, the difference was not significant $(P=0.06)$ between small and very small bulbs (table 4).

Table 4. Effect of bulbs size on the percentage of weight losses of bulbs during storage in 2008

\begin{tabular}{|c|c|c|c|}
\hline Growing season of bulbs & Storage duration (days) & Size of bulb & $\begin{array}{l}\text { Weight loss of bubs } \\
\text { (\%) }\end{array}$ \\
\hline \multirow{9}{*}{ Normal } & \multirow{3}{*}{75} & Large & $54.2^{\mathrm{a}} \pm 5.9$ \\
\hline & & Medium & $41.8^{\mathrm{b}} \pm 3.6$ \\
\hline & & Small & $50.01^{\mathrm{a}} \pm 1.4$ \\
\hline & \multirow{3}{*}{90} & Large & $60.2^{\mathrm{a}} \pm 3.3$ \\
\hline & & Medium & $49.4^{b} \pm 3.2$ \\
\hline & & Small & $56.0^{\mathrm{a}} \pm 1.1$ \\
\hline & \multirow{3}{*}{240} & Large & $85.6^{\mathrm{a}} \pm 1.3$ \\
\hline & & Medium & $77.9^{b} \pm 0.5$ \\
\hline & & Small & $79.0^{b} \pm 2.9$ \\
\hline \multirow{4}{*}{ Late } & \multirow{2}{*}{135} & Small & $51.1^{\mathrm{a}} \pm 1.8$ \\
\hline & & Very small & $42.8^{b} \pm 0.3$ \\
\hline & \multirow{2}{*}{150} & Small & $52.5^{\mathrm{a}} \pm 4.7$ \\
\hline & & Very small & $45.1^{\mathrm{a}} \pm 0.8$ \\
\hline
\end{tabular}

For the same storage duration, the averages of treatments affected by the same letter do not differ significantly at $5 \%$ level in Bonferroni multiple-comparison test 


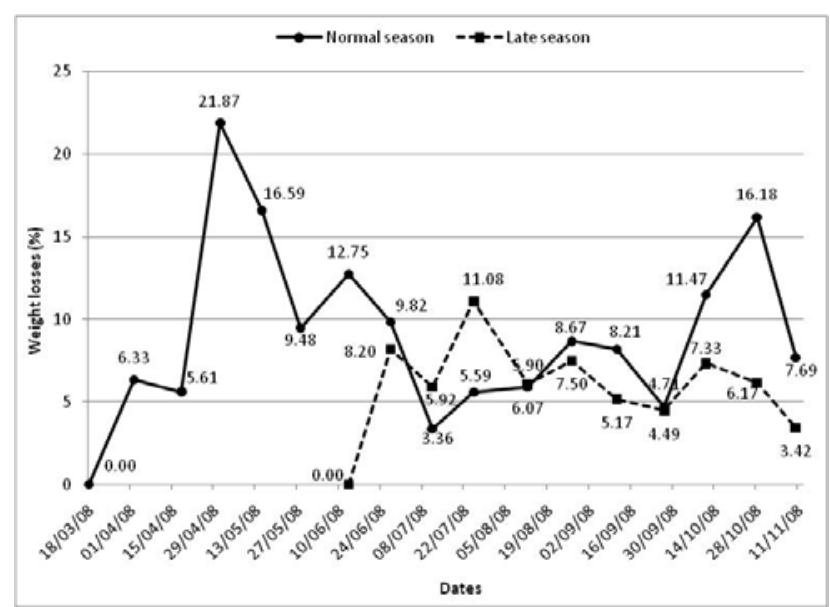

Fig 3: Evolution of the rates of weight loss of bulbs from normal and late season over the time of storage in 2008

\section{DISCUSSION}

Growing season of bulbs: It seems that the maximum losses were recorded at the same date for both types of bulbs, which suggests effect of an external factor. However, the observation of temperature and humidity did not reveal any sudden change that would justify this spike in bulb losses. For the bulbs from early season, low temperatures and low relative humidity at the beginning of storage could justify the low rate of weight losses in the first three months of storage. However, there is the high rate of losses in the first fortnight of storage of bulbs from the late season. It could be explained by latent infection or contamination of the bulbs by rot causing pathogens. These contaminated or infected bulbs could not be detected by eye examination at the time of sorting out the bulbs before storage.

The weight losses during the storage could not be correlated to factors such as temperature and relative humidity of storage environment. Indeed, for the trial in 2008, it emerged that the evolution of losses over time was the same for the two types of bulbs. However, the storage of these bulbs has not begun within the same climatic conditions. There has been a steady decline in maximum temperature and a steady rise in relative humidity while losses have changed unevenly. We note that the results of the trial in 2007 have also failed to establish a causal link between climatic factors and variations of weight losses.

The effect of the bulb production season is less pronounced over periods of conservation of about three months (84 days). Over longer periods like 150 days, we can observe that the bulbs produced during the late season (end of May harvest) are kept better compared to those produced in normal season (early March harvest). The reason would be that bulbs harvested earlier started to break their dormancy, and the breaking of the dormancy lead to leaf and root growth. That was probably influenced by the fall in temperature and increase in relative humidity that occurred at the start of the rainy season (figs $1 \mathrm{a}$ and 1b). Bulbs from the normal season were studied for eight months (240 days) against only five months (150 days) for the bulbs produced in late season. The latter would be relatively fresher. Our results are in perfect agreement with those of Sanon (1999) who showed that bulbs produced in the dry and hot season kept better than those produced during dry and cool weather. After five months of storage the cumulative percentage of weight losses for bulbs produced in normal season was $57.7 \pm 1.8 \%$ whereas the cumulative percentage of losses for bulbs produced in the late season was $49.3 \pm 3.0$ $\%$.The late season would therefore be more profitable in terms of reduction of losses when the growers or merchants plan to sell the onions in November to benefit from seasonal high prices.

Bulb size: The large bulbs have the disadvantage of losing weight more rapidly than the bulbs with medium or small size. This result confirms those of Ko et al. (2002) and those of Sanon (1999). For bulbs of the same variety, the dry matter content is independent of the bulbs size (Toledo et al., 1984). So, the higher absolute water content of bulbs may explain the rapid deterioration of the large bulbs during conservation. They would be less firm than small bulbs (Toledo et al., 1984; Chung, 1989). The harvest of the late season contained bulbs of only small and very small sizes that have longer storage life than the bulbs of the normal season. The good performance of small bulbs during storage at room temperature was also noted by ward (1979) and Ko et al. (2002). The latter found that the most suitable size of bulb for long term conservation was about 135 $\pm 37 \mathrm{~g}$.

By way of recommendations for a storage at room temperature, the crop of late season would be more appropriate under our experimental conditions. Furthermore, a choice of bulbs weighing within the range 50 and $150 \mathrm{~g}$ would provide a long time of conservation. In this weight class, $51.1 \pm 1.8 \%$ of losses were recorded indeed after 135 days for bulbs produced in the late season. However, the bulbs with the same size from the normal season have lost 50.0 $\pm 1.4 \%$, only after 75 days of storage. We find that 
the bulbs are fresher if they are produced in late season and should continue their physiological maturity during the storage phase called dormancy. If the bulbs have attained the physiological maturity, their dormancy can be removed by many environmental factors like high relative humidity and low temperatures. It was the case of bulbs harvested during normal season (March), conserved until October or November, so almost 7 to 8 months. We can note however, that yields are usually poor in the late season. It is less attractive for farmers to produce bulbs at this time. From this point of view, the normal season that offers the highest yields would be preferable to the late season. For such bulbs, it would be more beneficial to select those that would weigh between 150 and $200 \mathrm{~g}$. This weight class has recorded $49.4 \pm 3.2 \%$ of total losses after 90 days of storage, against $60.2 \pm 3.1 \%$ for the big bulbs and $56.0 \pm 1.1 \%$ for the small bulbs.

The reduction of losses during the storage of bulbs has always been a major worry for the producers. From results of this study, it seems that a judicious choice of the growing season is necessary if the storage is planned for a long time. It is more beneficial to produce in the late season with a lifting at the end of May than to produce earlier for lifting in early March. To extend the storage period, a farmer has two possibilities: The first one is to select bulbs weighing 50 to $150 \mathrm{~g}$ if they are produced in late season. In that case, it will be lost $51.1 \pm 1.8 \%$ of the weight losses of initial stock over a time of 135 days. The second possibility is to select bulbs weighing 150 to $200 \mathrm{~g}$ when it is a harvest from a normal season. The best time of storage will be 90 days with weight losses of $49.4 \pm 3.2 \%$ of the initial stock. The grower needs to have a good understanding of how to balance potential storage losses against increased value of the crop over time in order to decide the optimum time to sell the stored crop.

\section{ACKNOWLEDGMENTS:}

Authors thank Dr Soro Senan and Dr Dao Daouda from Swiss Centre for Scientific Research (CSRS) / Côte d'Ivoire for their support in data collecting and to Dr Andres Tschannen for the logistical support.

\section{REFERENCES}

Brewster, J.L (1994). Onions and other Vegetable Alliums. Wallingford (UK). CAB International. ISBN 085198753-2.

Chung, B (1989). Irrigation and bulb onion quality. Acta Hort. 247: 233-337.
Coolong, T.W. and Randle, W.M (2008). The effects of Calcium Chloride and Ammonium Sulfate on onion bulb quality at harvest and during storage. HortScience 43: $465-471$.

Foskett, R.L. and Peterson, C.E (1950). Relation of dry matter content to storage quality in some onion varieties and hybrids. Proc. Am. Soc. Hortic. Sci. 55: 314-318.

Ko, S.S., Chang, W.N., Wang, J.F., Cherng, S.J and Shanmugasundaram, S (2002). Storage variability among short-day onion cultivars under high temperature and high relative humidity, and its relationships with disease incidence and bulbs characteristics. J. Am. Soc. Hortic. Sci. 127: 848-854.

Peters, R (1990). Seed production in onions and some other Allium species. In: Onions and Allied Crops. Rabinowitch, H.D. and J.L. Brewster, (eds.). Vol. I. Botany, Physiology, and Genetics. CRC Press. Boca Raton. FL. pp. 161-176.

Ramin, A.A (1999). Storage potential of bulb onions (Allium cepa L.) under high temperature. J. Horticult. Sci. Biotechnol. 74: 181-186.

Sanon, M (1999). Optimisation de l'irrigation à la parcelle par radio-thermométrie, Application à une culture d'oignon (Allium cepa L.) en climat sahélien (nordouest du BF). Thèse de Docteur Mention : Génie rural et des procédés. ENSA de Rennes. $266 \mathrm{p}$.

Stow, J.R and Ward, C.M (1978). The effect of transfer from low to high temperature on losses of stored bulb onion (Allium cepa L.). Ann. Appl. Biol. 88: 193-7.

Toledo, J., Sherman, M and Huber, D.J (1984). Some effects of cultivar, bulb size and preharvest treatments on storage characteristics of North Florida onion. Proc. Fla. State Hortic. Soc. 97: 106-108.

Tucker, W.G and Drew, R.L.K (1982). Postharvest study on autumn bulb onions. The effect of harvest date, conditioning treatments, and field drying on skin quality and on storage performance. J. Hort. Sci. 57: 339-348.

Tucker, W.G., Stow J.R and Ward, C.M (1977). The high temperature storage of onion in the United Kingdom. Acta Hort. 62: 181-9.

Wall, M.M and Corgan, J.N (1994). Postharvest losses from delayed harvest and during common storage of shortdays onions. HortScience. 29: 802-804.

Ward, C.M (1976). The influence of temperature on weight loss from stored onion bulbs due to desiccation, respiration and sprouting. Ann. Appl. Biol. 83: 149-55.

Ward, C.M (1979). The effect of bulb size on the storagelife of onions. Ann. Appl. Biol. 91: 113-117. 